\section{Prevención de infecciones. Un vistazo a la nueva "Guía global para prevención de infecciones de sitio quirúrgico"}

\author{
Preventing infections by taking \\ a look at the new "Global \\ Guidelines for the Prevention of \\ Surgical Site Infection"
}

Las infecciones de sitio quirúrgico afectan a un tercio de los pacientes sometidos a un procedimiento de este tipo. En países de bajos y medianos recursos son más frecuentes que en los de altos recursos; las tasas de incidencia varían entre 1.2 y 23.6 por cada 100 cirugías y, en cirugía pediátrica, se reportan tasas de 12.7 por cada 100 cirugías (IC 95\%: 6.7 a 20.3).

En México, en los años 2014 y 2015, la Red Hospitalaria de Vigilancia Epidemiológica (RHOVE) reportó 15 infecciones de sitio quirúrgico por cada 100 egresos. En 2015 se reportó una tasa agrupada de 1.1 por cada 100 cirugías (incluyendo todos los hospitales) y de 0.8 por cada 100 cirugías cuando se consideran únicamente los hospitales pediátricos. El análisis por tipo de hospital, de acuerdo con el número de camas, reportó una tasa nacional de 1.7 infecciones de sitio quirúrgico por cada 100 cirugías para hospitales con más de 200 camas y de 1 por cada 100 cirugías para hospitales con menos de 200 camas. $^{1}$

Nuestro Instituto Nacional de Pediatría tiene más de 200 camas y en los últimos 5 años, de 2011 a 2015, las tasas de infección de sitio quirúrgico han sido de 1.1 , 1.8, 1.6, 1.5 y 1.3 por cada 100 cirugías. $^{2}$

Un estudio realizado en un hospital particular de México, en el período 2009-2010, reportó una tasa de infecciones de sitio quirúrgico de $0.52 \%$; advirtiendo que ésta podría estar subestimada debido a que el seguimiento sólo se hizo durante la estancia de los pacientes en el hospital y que el seguimiento de pacientes quirúrgicos durante este período tiende a subestimar tal incidencia cuando se le compara con la del seguimiento de pacientes post egreso. ${ }^{3}$ 
Una revisión sistemática, que incluyó 55 estudios, mostró que $60 \%$ de las infecciones de sitio quirúrgico aparecen después del alta del paciente, con cifras de 13.5 a $94.8 \%$ en los diferentes estudios incluidos. ${ }^{4}$ Otro estudio, realizado en el Instituto Nacional de Cancerología, en el que se realizó vigilancia prospectiva durante los 30 días posteriores a los procedimientos quirúrgicos reportó un incremento de la detección de infecciones de sitio quirúrgico de $400 \%$ (i.e. 9 vs. 1.8 por cada 100 cirugías). ${ }^{5}$

Generalmente, en la mayoría de los hospitales las tasas de infección captadas por el sistema de vigilancia son similares a las mencionadas; se registran infectados que regresan al hospital por la gravedad del caso o las que se detectan durante la hospitalización. La mayoría de las infecciones de poca importancia clínica no son reportadas por el equipo quirúrgico a los comités de prevención y control de infecciones. Por esta razón en el Instituto Nacional de Pediatría hemos pedido a la clínica de estomas que reporte cualquier infección con la finalidad de disminuir esta brecha de notificación.

En Estados Unidos y Europa la infección de sitio quirúrgico es la segunda causa de infecciones asociadas a la atención de la salud (IAAS); es por ello que se ha desarrollado la Guía global para prevención de infecciones de sitio quirúrgico. Ésta trata de dar un panorama general del problema y estandarizar las medidas de prevención durante todo el proceso: el espacio pre, durante y post operatorio. ${ }^{1}$

Algunos de los puntos más relevantes presentados en la guía son el reporte de la resistencia antimicrobiana asociada con la infección de sitio quirúrgico en Estados Unidos, en donde 43.7\% de $S$. aureus fue oxacilino-meticilino resistente; $7.9 \%$ de Klebsiella pneumoniae fue resistente al carbapenems; $6.2 \%$ de $E$. faecalis fue resistente a la vancomicina y $25.3 \%$ de $E$. coli fue resistente a las fluoroquinolonas. ${ }^{1}$

Por otra parte, la guía consigna que el aumento de la estancia hospitalaria por la infección de sitio quirúrgico es de 9.7 días más, con un costo de $\$ 20,842$ dólares americanos por ingreso. El costo calculado por una infección de sitio quirúrgico es entre \$1,087 a 29,443 dólares americanos. ${ }^{1}$ En México se ha reportado una estancia hospitalaria de 7 hasta 20.7 días adicionales, debida a infección de sitio quirúrgico, con un costo unitario de $\$ 113,880.62$ pesos mexicanos. ${ }^{6-7}$

\section{FACTORES DE RIESGO EN CIRUGÍA}

Los factores documentados son el índice de masa corporal alto (obesidad), diabetes, cirugía en la que se prolonga el tiempo quirúrgico, estancia hospitalaria antes de la cirugía por dos días, la no aplicación de profilaxis antibiótica durante la primera hora antes de la cirugía, heridas contaminadas o sucias, traumatismos, re-operar al paciente. Algunos estudios han identificado una relación inversa entre el número de cirugías efectuadas por los cirujanos y la tasa de infecciones de sitio quirúrgico. ${ }^{1}$

Medio ambiente: durante muchos años la contaminación ambiental no fue considerada importante, a diferencia de muchos otros factores que contribuyen a las infecciones de sitio quirúrgico; sin embargo, la evidencia reciente ha mostrado que un ambiente contaminado desempeña un papel importante en la transmisión de microorganismos. Es esencial que la sala de operaciones se limpie a fondo diariamente; la ventilación y el aire acondicionado deben ser adecuados para filtrar el aire contaminado que entra al quirófano, así como disminuir la polución de microorganismos de las escamas de la piel.

Al principio de cada día todas las superficies deben limpiarse con un paño húmedo, de micro- 
fibra, limpio y sin pelusas, con el desinfectante adecuado y siguiendo las instrucciones del fabricante. Se utilizan desinfectantes de bajo nivel como el hipoclorito de sodio o el peróxido de hidrogeno. Entre cada cirugía deben limpiarse las superficies tocadas frecuentemente por las manos, así como aquellas que pueden tener contacto con la sangre o fluidos corporales de los pacientes. Se limpian primero usando una solución de detergente y luego el desinfectante de acuerdo con la política del hospital y dejando secar perfectamente las superficies antes de volver a usarlas (Figura 1).
Descontaminación, limpieza, desinfección y esterilización de equipo e instrumental: es otra de las partes fundamentales de prevención de infecciones de sitio quirúrgico siguiendo la clasificación de descontaminación de equipo de Spaulding. ${ }^{1}$

Recomendaciones de la guía: en el Cuadro 1 se muestran las recomendaciones de prevención, pre, intra y post-operatoria; sin embargo, hay que hacer notar que muchas de ellas, como en otras guías, sólo se documentan para población adulta, por ello es importante realizar estudios

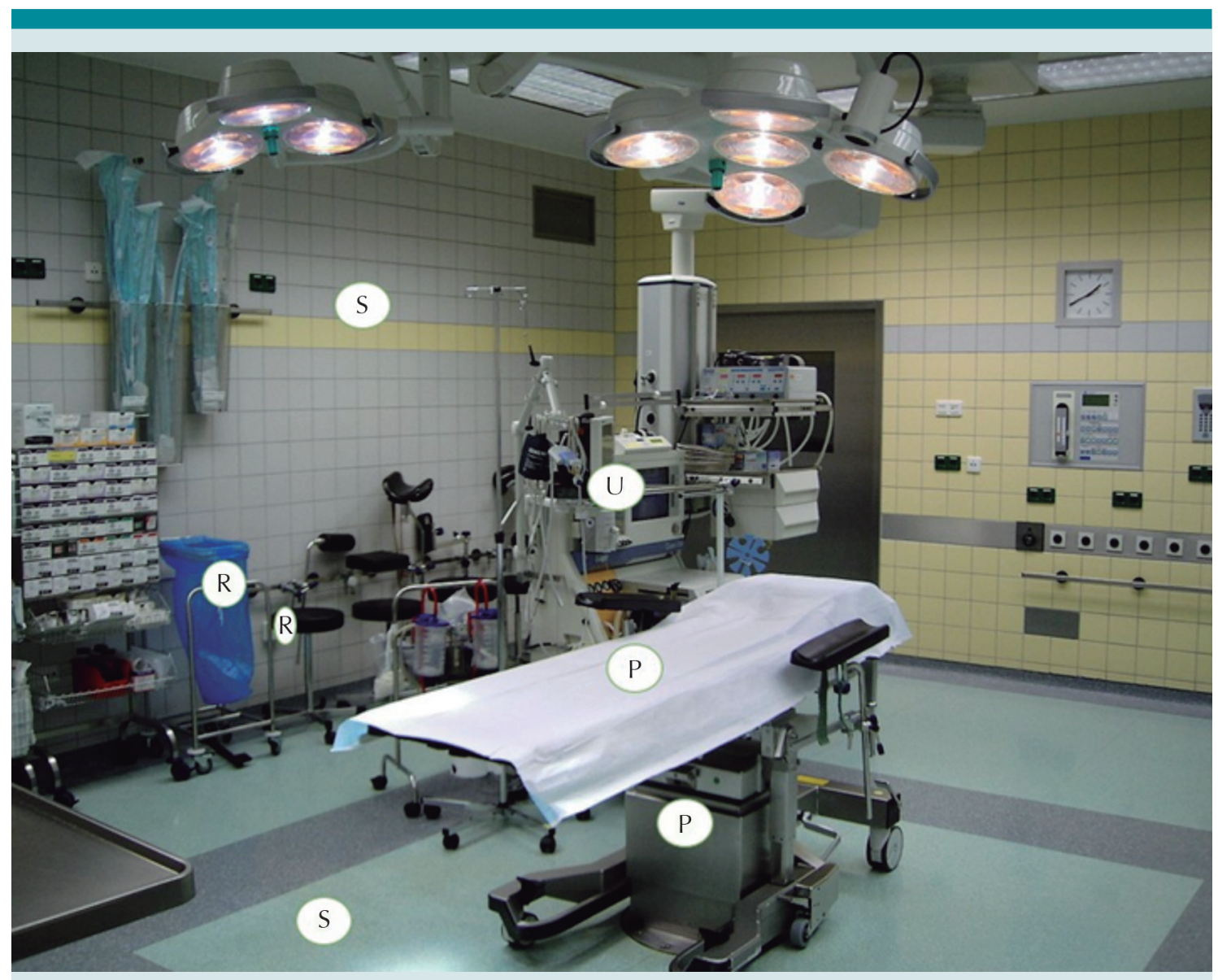

Figura 1. Limpieza de superficies de acuerdo con el grado de contaminación entre cada cirugía. P: limpiar entre cada paciente; U: limpiar después de uso en el paciente; R: reforzar la limpieza; S: limpiar sólo si está sucio. 
Cuadro 1. Recomendaciones para la prevención de infecciones ${ }^{1}$ (Continúa en la siguiente página)

\begin{tabular}{|c|c|c|c|c|}
\hline Tema & Pregunta a investigar & Recomendación & Evidencia & $\begin{array}{c}\text { Calidad de la } \\
\text { evidencia }\end{array}$ \\
\hline \multicolumn{5}{|c|}{ Medidas preoperatorias } \\
\hline $\begin{array}{l}\text { Baño preopera- } \\
\text { torio }\end{array}$ & $\begin{array}{l}\text { 1. ¿Es el baño con jabón antimi- } \\
\text { crobial más efectivo que el baño } \\
\text { con jabón común para disminuir } \\
\text { infecciones de sitio quirúrgico? } \\
\text { 2. ¿Es el baño preoperatorio con } \\
\text { toallas impregnadas de gluconato } \\
\text { de clorhexidina impregnado más } \\
\text { eficaz comparado con el baño } \\
\text { con jabón antimicrobiano? }\end{array}$ & $\begin{array}{l}\text { Es una buena práctica clínica que } \\
\text { los pacientes se bañen o duchen } \\
\text { antes de la cirugía. Se sugiere que } \\
\text { el jabón natural o un jabón anti- } \\
\text { microbiano pueden ser utilizados } \\
\text { para este fin. } \\
\text { El panel decidió no recomendar } \\
\text { el uso de paños impregnados } \\
\text { de gluconato de clorhexidina } \\
\text { (para reducir infecciones de sitio } \\
\text { quirúrgico) debido a la muy baja } \\
\text { calidad de la evidencia }\end{array}$ & Condicional & Moderada \\
\hline \multirow[t]{2}{*}{$\begin{array}{l}\text { Descolonización } \\
\text { con mupirocina } \\
\text { ungüento (con o } \\
\text { sin gluconato de } \\
\text { clorhexidina) para } \\
\text { prevenir infección } \\
\text { por } S \text {. aureus en } \\
\text { portadores nasales }\end{array}$} & $\begin{array}{l}\text { ¿Es eficaz el uso del ungüento } \\
\text { de mupirocina nasal (con o sin } \\
\text { gluconato de clorhexidina) en } \\
\text { portadores nasales sometidos a } \\
\text { cirugía para reducir el número de } \\
\text { infecciones por } S \text {. aureus? }\end{array}$ & $\begin{array}{l}\text { El panel recomienda que los } \\
\text { pacientes sometidos a cirugía car- } \\
\text { diotorácica y ortopédica que sean } \\
\text { conocidos como colonizados de } \\
\text { S. aureus deben recibir ungüento } \\
\text { al } 2 \% \text { de mupirocina intranasal } \\
\text { (con o sin gluconato de clorhexi- } \\
\text { dina) perioperatoria. }\end{array}$ & Fuerte & Moderada \\
\hline & & $\begin{array}{l}\text { El panel sugiere considerar usarla } \\
\text { también en pacientes colonizados } \\
\text { con S. aureus nasal de otros tipos } \\
\text { de cirugía }\end{array}$ & Condicional & Moderada \\
\hline $\begin{array}{l}\text { Colonización de } \\
\text { bacterias produc- } \\
\text { toras de betalacta- } \\
\text { masa de espectro } \\
\text { extendido y el im- } \\
\text { pacto de profilaxis } \\
\text { antibiótica }\end{array}$ & $\begin{array}{l}\text { 1. ¿Debería la profilaxis quirúrgi- } \\
\text { ca antibiótica ser modificada en } \\
\text { áreas de prevalencia alta (> } 10 \%) \\
\text { de bacterias productoras de beta- } \\
\text { lactamasa de espectro extendido? } \\
\text { 2. ¿Debe la profilaxis quirúrgica } \\
\text { antibiótica ser modificada en pa- } \\
\text { cientes colonizados con bacterias } \\
\text { productoras de betalactamasa } \\
\text { de espectro extendido o que son } \\
\text { portadores? } \\
\text { 3. ¿Debería realizarse tamizaje } \\
\text { para bacterias productoras de be- } \\
\text { talactamasa de espectro extendido } \\
\text { a los pacientes antes de la cirugía? }\end{array}$ & $\begin{array}{l}\text { No se da recomendación por falta } \\
\text { de evidencia }\end{array}$ & $\begin{array}{l}\text { No } \\
\text { evidencia }\end{array}$ & No evidencia \\
\hline \multirow[t]{2}{*}{$\begin{array}{l}\text { Profilaxis quirúrgi- } \\
\text { ca antimicrobiana } \\
\text { en el tiempo } \\
\text { correcto }\end{array}$} & $\begin{array}{l}\text { ¿Cómo funciona la administración } \\
\text { profilaxis quirúrgica antibiótica } \\
\text { en el momento óptimo para dis- } \\
\text { minuir el riesgo de infecciones de } \\
\text { sitio quirúrgico? }\end{array}$ & $\begin{array}{l}\text { El panel recomienda que la profi- } \\
\text { laxis quirúrgica antibiótica debe ser } \\
\text { administrada antes de la incisión } \\
\text { quirúrgica. Cuando se indica (de- } \\
\text { pendiendo del tipo de operación). }\end{array}$ & Fuerte & Baja \\
\hline & & $\begin{array}{l}\text { El panel recomienda la adminis- } \\
\text { tración de profilaxis quirúrgica } \\
\text { antibiótica dentro de los } 120 \\
\text { minutos antes de la incisión, } \\
\text { considerando la vida media del } \\
\text { antibiótico }\end{array}$ & Fuerte & Moderada \\
\hline
\end{tabular}


Cuadro 1. Recomendaciones para la prevención de infecciones ${ }^{1}$ (Continúa en la siguiente página)

\begin{tabular}{|c|c|c|c|c|}
\hline Tema & Pregunta a investigar & Recomendación & Evidencia & $\begin{array}{c}\text { Calidad de la } \\
\text { evidencia }\end{array}$ \\
\hline \multirow[t]{2}{*}{$\begin{array}{l}\text { Preparación del } \\
\text { intestino y uso de } \\
\text { antibióticos orales }\end{array}$} & $\begin{array}{l}\text { ¿Es la preparación del intestino } \\
\text { combinada con o sin antibiótico } \\
\text { oral eficaz para la prevención de } \\
\text { infecciones de sitio quirúrgico en } \\
\text { cirugía colorrectal? }\end{array}$ & $\begin{array}{l}\text { Se sugiere que los antibióticos } \\
\text { orales preoperatorios, combinados } \\
\text { con la preparación del intestino, } \\
\text { deben ser utilizados para reducir } \\
\text { el riesgo de infecciones de sitio } \\
\text { quirúrgico en pacientes adultos } \\
\text { sometidos a cirugía colorrectal } \\
\text { electiva }\end{array}$ & Condicional & Moderada \\
\hline & & $\begin{array}{l}\text { Se recomienda que la sola } \\
\text { preparación del intestino (sin } \\
\text { administración oral de antibióti- } \\
\text { cos) no debe ser utilizado con el } \\
\text { fin de reducir infecciones de sitio } \\
\text { quirúrgico en adultos sometidos a } \\
\text { cirugía colorrectal electiva }\end{array}$ & Alto & Moderada \\
\hline $\begin{array}{l}\text { Remoción de } \\
\text { vello o pelo }\end{array}$ & $\begin{array}{l}\text { 1. ¿La depilación afecta la inci- } \\
\text { dencia de infecciones de sitio } \\
\text { quirúrgico? } \\
\text { 2. ¿Qué método y qué momento } \\
\text { de realización de la depilación } \\
\text { están asociados con la reducción } \\
\text { de infecciones de sitio quirúrgico? }\end{array}$ & $\begin{array}{l}\text { Se recomienda que en pacien- } \\
\text { tes sometidos a procedimiento } \\
\text { quirúrgico, no debe ser eliminado } \\
\text { el cabello o vello. Si es absolu- } \\
\text { tamente necesario, sólo debe ser } \\
\text { removido con clipper removedor } \\
\text { quirúrgico de vello. El afeitado } \\
\text { está fuertemente prohibido en } \\
\text { todo el tiempo, ya sea preoperato- } \\
\text { rio o en el quirófano }\end{array}$ & Fuerte & Moderada \\
\hline $\begin{array}{l}\text { Preparación del } \\
\text { sitio de incisión }\end{array}$ & $\begin{array}{l}\text { ¿Se deben usar solución alcoho- } \\
\text { lada antisépticas o soluciones } \\
\text { acuosas para las preparaciones de } \\
\text { la piel en pacientes quirúrgicos? } \\
\text { y, más específicamente, ¿debería } \\
\text { usarse soluciones de gluconato de } \\
\text { clorhexidina o yodopovidona? }\end{array}$ & $\begin{array}{l}\text { Se recomienda uso de antiséptico } \\
\text { a base de alcohol o soluciones } \\
\text { basadas en gluconato de clorhexi- } \\
\text { dina para preparación de la piel } \\
\text { en el sitio quirúrgico en pacien- } \\
\text { tes sometidos a procedimientos } \\
\text { quirúrgicos }\end{array}$ & Fuerte & $\begin{array}{c}\text { Baja a } \\
\text { moderada }\end{array}$ \\
\hline $\begin{array}{l}\text { Uso de antimicro- } \\
\text { bianos tópicos }\end{array}$ & $\begin{array}{l}\text { ¿Se recomienda el uso de antimi- } \\
\text { crobianos tópicos además de la } \\
\text { preparación de la piel comparado } \\
\text { con sólo la preparación de la piel? }\end{array}$ & $\begin{array}{l}\text { Se recomienda que no se use la } \\
\text { aplicación de antimicrobianos } \\
\text { tópicos después de la prepara- } \\
\text { ción de la piel con el objetivo de } \\
\text { disminuir las infecciones de sitio } \\
\text { quirúrgico }\end{array}$ & Condicional & Muy baja \\
\hline Higiene de manos & $\begin{array}{l}\text { 1. ¿Cuál es el tipo de producto } \\
\text { eficaz para la higiene de manos } \\
\text { quirúrgica para prevenir infeccio- } \\
\text { nes de sitio quirúrgico? } \\
\text { 2. ¿Cuál es la técnica eficaz y } \\
\text { la duración ideal de higiene de } \\
\text { manos en cirugía? }\end{array}$ & $\begin{array}{l}\text { Se recomienda realizar la higiene } \\
\text { de manos por frotando con una } \\
\text { adecuado jabón antimicrobiano y } \\
\text { agua o usar una base de solución } \\
\text { alcoholada antes de ponerse los } \\
\text { guantes estériles }\end{array}$ & Fuerte & Moderada \\
\hline $\begin{array}{l}\text { Mantener la ade- } \\
\text { cuada temperatu- } \\
\text { ra/normotermia) }\end{array}$ & $\begin{array}{l}\text { ¿Se debe o no mantener el calen- } \\
\text { tamiento corporal para disminuir } \\
\text { las infecciones de sitio quirúrgico? }\end{array}$ & $\begin{array}{l}\text { Se sugiere el uso de procedimien- } \\
\text { tos y dispositivos de calenta- } \\
\text { miento corporal en el quirófano } \\
\text { durante la cirugía } \\
\text { con el propósito de reducir infec- } \\
\text { ciones de sitio quirúrgico }\end{array}$ & Condicional & Moderada \\
\hline
\end{tabular}


Cuadro 1. Recomendaciones para la prevención de infecciones ${ }^{1}$ (Continúa en la siguiente página)

\begin{tabular}{|c|c|c|c|c|}
\hline Tema & Pregunta a investigar & Recomendación & Evidencia & $\begin{array}{c}\text { Calidad de la } \\
\text { evidencia }\end{array}$ \\
\hline \multirow[t]{2}{*}{$\begin{array}{l}\text { Uso de protocolos } \\
\text { para el control } \\
\text { intensivo de la } \\
\text { glucosa periope- } \\
\text { ratoria }\end{array}$} & $\begin{array}{l}\text { 1. ¿Si se tienen protocolos para } \\
\text { mantener los niveles de glucosa } \\
\text { en sangre perioperatoria óptimos } \\
\text { se reducen las infecciones de sitio } \\
\text { quirúrgico? }\end{array}$ & $\begin{array}{l}\text { 1. Se sugiere el uso de protoco- } \\
\text { los para el control del nivel de } \\
\text { glucosa perioperatoria en adultos } \\
\text { diabéticos y no diabéticos que } \\
\text { serán sometidos a cirugía para } \\
\text { reducir el riesgo de infecciones de } \\
\text { sitio quirúrgico }\end{array}$ & Condicional & Ваја \\
\hline & $\begin{array}{l}\text { 2. ¿Cuál es el nivel óptimo de } \\
\text { glucosa en sangre perioperatoria } \\
\text { en pacientes diabéticos y no } \\
\text { diabéticos? }\end{array}$ & $\begin{array}{l}\text { 2. No se recomienda ningún nivel } \\
\text { óptimo especifico de glucosa por } \\
\text { la falta de evidencia }\end{array}$ & & \\
\hline $\begin{array}{l}\text { Mantener el } \\
\text { adecuado volumen } \\
\text { circulante (normo- } \\
\text { volemia) }\end{array}$ & $\begin{array}{l}\text { ¿El uso de un manejo especifico } \\
\text { de líquidos durante la cirugía } \\
\text { afecta el riesgo de infecciones de } \\
\text { sitio quirúrgico? }\end{array}$ & $\begin{array}{l}\text { Se sugiere el uso adecuado de } \\
\text { manejo de líquidos intraopera- } \\
\text { torios para reducir el riesgo de } \\
\text { infecciones de sitio quirúrgico }\end{array}$ & Condicional & Baja \\
\hline \multirow[t]{2}{*}{ Campos y batas } & $\begin{array}{l}\text { 1. ¿Existe alguna diferencia en las } \\
\text { tasas de infección de sitio qui- } \\
\text { rúrgico dependiendo del uso de } \\
\text { campos y batas desechables o no? }\end{array}$ & $\begin{array}{l}\text { Se sugiere el uso de campos y } \\
\text { batas estériles durante la cirugía } \\
\text { sin importar sean desechables } \\
\text { o no para disminuir el riesgo de } \\
\text { infecciones de sitio quirúrgico }\end{array}$ & Condicional & Moderada \\
\hline & $\begin{array}{l}\text { 2. ¿El uso de campos para el } \\
\text { sitio de incisión desechables o } \\
\text { adheribles influye en el riesgo de } \\
\text { infecciones de sitio quirúrgico? }\end{array}$ & $\begin{array}{l}\text { Se sugiere no usar el uso de } \\
\text { campos adhesivos plásticos con o } \\
\text { sin antimicrobianos para prevenir } \\
\text { infecciones de sitio quirúrgico }\end{array}$ & Condicional & $\begin{array}{l}\text { Baja o muy } \\
\text { baja }\end{array}$ \\
\hline $\begin{array}{l}\text { Protectores de la } \\
\text { herida }\end{array}$ & $\begin{array}{l}\text { ¿El uso de protectores de la herida } \\
\text { disminuye las infecciones de sitio } \\
\text { quirúrgico en cirugía abdominal } \\
\text { abierta? }\end{array}$ & $\begin{array}{l}\text { Se sugiere considerar el uso de } \\
\text { dispositivos protectores en pro- } \\
\text { cedimientos con heridas limpias } \\
\text { contaminadas, contaminadas y } \\
\text { sucias, de cirugía abdominal para } \\
\text { disminuir la tasa de infecciones de } \\
\text { sitio quirúrgico }\end{array}$ & Condicional & Muy baja \\
\hline \multirow[t]{3}{*}{$\begin{array}{l}\text { Irrigación de heri- } \\
\text { da quirúrgica }\end{array}$} & $\begin{array}{l}\text { ¿La irrigación intraoperatoria de la } \\
\text { herida reduce el riesgo de infec- } \\
\text { ciones de sitio quirúrgico? }\end{array}$ & $\begin{array}{l}\text { No hay suficiente evidencia para } \\
\text { recomendar irrigación con solu- } \\
\text { ción salina de la herida antes de } \\
\text { cerrar para prevenir infecciones } \\
\text { de sitio quirúrgico }\end{array}$ & $\begin{array}{l}\text { No hay } \\
\text { evidencia }\end{array}$ & $\begin{array}{l}\text { No hay evi- } \\
\text { dencia }\end{array}$ \\
\hline & & $\begin{array}{l}\text { Se sugiere considerar el uso } \\
\text { de irrigación de la herida con } \\
\text { solución acuosa de yodopovido- } \\
\text { na antes del cierre para prevenir } \\
\text { infecciones de sitio quirúrgico, } \\
\text { particularmente en heridas limpias } \\
\text { y limpias contaminadas }\end{array}$ & Condicional & Baja \\
\hline & & $\begin{array}{l}\text { Se sugiere que el uso de irrigacio- } \\
\text { nes con antibióticos no debe ser } \\
\text { usado con el propósito de preve- } \\
\text { nir infecciones de sitio quirúrgico }\end{array}$ & Condicional & Baja \\
\hline
\end{tabular}


Cuadro 1. Recomendaciones para la prevención de infecciones ${ }^{1}$ (Continúa en la siguiente página)

\begin{tabular}{|c|c|c|c|c|}
\hline Tema & Pregunta a investigar & Recomendación & Evidencia & $\begin{array}{c}\text { Calidad de la } \\
\text { evidencia }\end{array}$ \\
\hline $\begin{array}{l}\text { Uso de apósitos } \\
\text { profilácticos con } \\
\text { presión negativa } \\
\text { en la herida }\end{array}$ & $\begin{array}{l}\text { ¿El uso de apósitos profilácticos } \\
\text { con presión negativa de la herida } \\
\text { reduce las tasas de infecciones de } \\
\text { sitio quirúrgico comparado con } \\
\text { el uso convencional de apósitos } \\
\text { convencionales? }\end{array}$ & $\begin{array}{l}\text { Se sugiere el uso de apósitos } \\
\text { profilácticos con presión negativa } \\
\text { en pacientes adultos en el cierre } \\
\text { primario de la incisión en heridas } \\
\text { de alto riesgo para prevenir infec- } \\
\text { ciones de sitio quirúrgico }\end{array}$ & Condicional & Baja \\
\hline $\begin{array}{l}\text { Uso de guantes } \\
\text { quirúrgicos }\end{array}$ & $\begin{array}{l}\text { 1. ¿Cuándo se recomienda el uso } \\
\text { de doble guante? } \\
\text { 2. ¿Cuál es el criterio para cam- } \\
\text { biar guante durante la cirugía? } \\
\text { 3. ¿Qué tipo de guantes deben } \\
\text { usarse? }\end{array}$ & $\begin{array}{l}\text { No se dan recomendaciones por } \\
\text { falta de evidencia respecto al uso } \\
\text { de doble guantes o cambio de } \\
\text { guantes durante la cirugía o el uso } \\
\text { de un tipo específico de guantes } \\
\text { como más efectivo para reducir } \\
\text { el riesgo de infecciones de sitio } \\
\text { quirúrgico }\end{array}$ & $\begin{array}{c}\text { No } \\
\text { evidencia }\end{array}$ & No evidencia \\
\hline $\begin{array}{l}\text { Cambio de } \\
\text { instrumental } \\
\text { quirúrgico }\end{array}$ & $\begin{array}{l}\text { ¿Debe cambiarse el set del equipo } \\
\text { de instrumental al cerrar la herida } \\
\text { entre tejido subcutáneo y piel } \\
\text { para disminuir el riesgo de infec- } \\
\text { ciones de sitio quirúrgico? }\end{array}$ & $\begin{array}{l}\text { No existe evidencia para reco- } \\
\text { mendar esto }\end{array}$ & No evidencia & No evidencia \\
\hline $\begin{array}{l}\text { Uso de sutura con } \\
\text { antimicrobianos }\end{array}$ & $\begin{array}{l}\text { ¿Debe usarse sutura con antimi- } \\
\text { crobianos? Si la respuesta es sí, } \\
\text { ¿cuándo? ¿cómo? }\end{array}$ & $\begin{array}{l}\text { Se sugiere el uso de sutura con } \\
\text { antiséptico con el propósito de } \\
\text { reducir el riesgo de infecciones } \\
\text { de sitio quirúrgico independiente- } \\
\text { mente del tipo de cirugía }\end{array}$ & Condicional & Moderada \\
\hline \multirow[t]{2}{*}{$\begin{array}{l}\text { Ventilación con } \\
\text { flujo laminar en } \\
\text { quirófano }\end{array}$} & $\begin{array}{l}\text { 1. ¿El uso de flujo laminar en el } \\
\text { quirófano se asocia con reducción } \\
\text { de infecciones de sitio quirúrgico? }\end{array}$ & $\begin{array}{l}\text { El uso de flujo laminar no debe } \\
\text { ser usado para disminuir el riesgo } \\
\text { de infecciones de sitio quirúrgico } \\
\text { para pacientes con artroplastia } \\
\text { total }\end{array}$ & Condicional & $\begin{array}{c}\text { Baja o muy } \\
\text { baja }\end{array}$ \\
\hline & $\begin{array}{l}\text { 2. ¿El uso de ventiladores o enfria- } \\
\text { dores incrementa las infecciones } \\
\text { de sitio quirúrgico? } \\
\text { 3. ¿La ventilación natural es una } \\
\text { alternativa aceptable para la venti- } \\
\text { lación mecánica? }\end{array}$ & $\begin{array}{l}\text { No se formulan recomendacio- } \\
\text { nes sobre el uso de ventiladores, } \\
\text { enfriadores o ventilación natural } \\
\text { por no existir evidencia }\end{array}$ & $\begin{array}{l}\text { No hay } \\
\text { evidencia }\end{array}$ & $\begin{array}{l}\text { No hay } \\
\text { evidencia }\end{array}$ \\
\hline \multicolumn{5}{|c|}{ Medidas preoperatorias e intraoperatorias } \\
\hline $\begin{array}{l}\text { Mejorar el apoyo } \\
\text { nutricional }\end{array}$ & $\begin{array}{l}\text { ¿Se debe mejorar el soporte } \\
\text { nutricional en el paciente para } \\
\text { prevenir infecciones de sitio } \\
\text { quirúrgico? }\end{array}$ & $\begin{array}{l}\text { Se sugiere considerar la adminis- } \\
\text { tración oral o enteral de nutrientes } \\
\text { múltiples mejorados o fórmu- } \\
\text { las nutricionales para prevenir } \\
\text { infecciones de sitio quirúrgico en } \\
\text { pacientes de bajo peso sometidos } \\
\text { a cirugías mayores }\end{array}$ & Condicional & Muy baja \\
\hline $\begin{array}{l}\text { Retirar agentes } \\
\text { inmunosupresores }\end{array}$ & $\begin{array}{l}\text { ¿Se deben retirar los agentes } \\
\text { inmunosupresores en el perio- } \\
\text { peratorio y esto disminuye las } \\
\text { infecciones de sitio quirúrgico? }\end{array}$ & $\begin{array}{l}\text { Se sugiere retirar la terapia inmu- } \\
\text { nosupresora antes de la cirugía } \\
\text { con el objeto de disminuir las } \\
\text { infecciones de sitio quirúrgico }\end{array}$ & Condicional & Muy baja \\
\hline
\end{tabular}


Cuadro 1. Recomendaciones para la prevención de infecciones (Continuación)

\begin{tabular}{|c|c|c|c|c|}
\hline Tema & Pregunta a investigar & Recomendación & Evidencia & $\begin{array}{c}\text { Calidad de la } \\
\text { evidencia }\end{array}$ \\
\hline $\begin{array}{l}\text { Oxigenación } \\
\text { perioperatoria }\end{array}$ & $\begin{array}{l}\text { ¿Qué tan seguro y efectivo es } \\
\text { aumentar la fracción inspiratoria } \\
\text { de oxigeno perioperatorio y esto } \\
\text { disminuye las infecciones de sitio } \\
\text { quirúrgico? }\end{array}$ & $\begin{array}{l}\text { Se recomienda que el paciente } \\
\text { adulto bajo anestesia general } \\
\text { con intubación endotraqueal } \\
\text { debe recibir } 80 \% \text { de fracción de } \\
\text { oxigeno inspiratorio durante el } \\
\text { procedimiento quirúrgico y si es } \\
\text { posible inmediatamente en el } \\
\text { postoperatorio durante } 2 \text { a } 6 \text { horas } \\
\text { para disminuir infecciones de sitio } \\
\text { quirúrgico }\end{array}$ & Fuerte & Moderada \\
\hline \multicolumn{5}{|c|}{ Medidas postoperatorias } \\
\hline $\begin{array}{l}\text { Prolongación de } \\
\text { profilaxis anti- } \\
\text { biótica }\end{array}$ & $\begin{array}{l}\text { ¿El continuar la profilaxis antibió- } \\
\text { tica reduce el riesgo de infeccio- } \\
\text { nes de sitio quirúrgico comparado } \\
\text { con el uso de profilaxis preopera- } \\
\text { toria e intraoperatoria indicada? }\end{array}$ & $\begin{array}{l}\text { No debe usarse profilaxis antibió- } \\
\text { tica después de terminar la cirugía } \\
\text { para prevenir infecciones de sitio } \\
\text { quirúrgico }\end{array}$ & Fuerte & Moderada \\
\hline $\begin{array}{l}\text { Uso de apósitos } \\
\text { especiales }\end{array}$ & $\begin{array}{l}\text { ¿Se deben usar apósitos especiales } \\
\text { o apósitos estándar estériles para } \\
\text { la prevención de infecciones de } \\
\text { sitio quirúrgico? }\end{array}$ & $\begin{array}{l}\text { No se sugiere el uso de apósi- } \\
\text { tos especiales sobre el uso de } \\
\text { apósitos estándar estériles en } \\
\text { cirugías de cierre primario con el } \\
\text { propósito de prevenir infecciones } \\
\text { de sitio quirúrgico }\end{array}$ & Condicional & Baja \\
\hline \multirow[t]{2}{*}{$\begin{array}{l}\text { Uso de profilaxis } \\
\text { en caso de dre- } \\
\text { naje o un tiempo } \\
\text { óptimo de retiro } \\
\text { del drenaje }\end{array}$} & $\begin{array}{l}\text { 1. ¿En presencia de drenajes, se } \\
\text { debe dar profilaxis antibiótica } \\
\text { para prevenir infecciones de sitio } \\
\text { quirúrgico? }\end{array}$ & $\begin{array}{l}\text { La profilaxis antibiótica no debe } \\
\text { ser continuada en la presencia } \\
\text { de drenajes con el propósito de } \\
\text { disminuir infecciones de sitio } \\
\text { quirúrgico }\end{array}$ & Condicional & Baja \\
\hline & $\begin{array}{l}\text { 2. ¿Cuándo se usan drenajes, qué } \\
\text { tanto tiempo se deben mantener } \\
\text { para minimizar el riesgo de com- } \\
\text { plicación de infecciones de sitio } \\
\text { quirúrgico? }\end{array}$ & $\begin{array}{l}\text { Se sugiere remover el drena- } \\
\text { je cuando clínicamente esté } \\
\text { indicado. No hay evidencia para } \\
\text { determinar un tiempo de retiro del } \\
\text { drenaje para prevenir infecciones } \\
\text { de sitio quirúrgico }\end{array}$ & Condicional & Muy baja \\
\hline
\end{tabular}

en los que se usen estas recomendaciones en poblaciones pediátricas y su publicación, para documentar si pueden ser aplicadas.

Por su evidencia las recomendaciones de esta guía fueron calificadas como "fuertes", cuando el panel estaba seguro que los beneficios de la intervención superaban a los riesgos o "condicionales" y cuando se consideró que los beneficios de la intervención probablemente superaban a los riesgos. Las recomendaciones se formularon por consenso, utilizando las herramientas de Cochrane para evaluación de riesgo de sesgo de estudios clínicos y la escala de calidad de Newcastle-Ottawa para estudios de cohorte. El grado de la calidad de la evidencia se ha clasificado de acuerdo con la documentación científica que apoya las recomendaciones en alta si el panel estaba muy seguro de que el verdadero efecto está cerca de la estimación del efecto; moderada si el panel tenía una confianza moderada en que la estimación del efecto era co- 
rrecta: el verdadero efecto es probable que esté cerca de la estimación del efecto pero existe la posibilidad de que sea sustancialmente diferente; baja si la confianza del panel en la estimación del efecto era limitada: el efecto real puede ser sustancialmente diferente de la estimación del efecto; muy baja si tenía muy poca confianza en la estimación del efecto: es probable que el efecto real sea substancialmente diferente de la estimación del efecto.

\section{CONCLUSIONES}

El objetivo de dar a conocer estas guías es mejorar la calidad de la atención en los pacientes que son sometidos a procedimientos quirúrgicos, teniendo como efecto secundario el prevenir las infecciones de sitio quirúrgico. La adopción de las directrices por parte de todos los involucrados: personal de salud, pacientes y cualquier persona que intervenga directamente o indirectamente en el proceso, así como los administrativos que gestionan recursos, es vital, y una herramienta más que complementa las listas de verificación de cirugía segura, para lograr la reducción del riesgo y daños que pueden ser provocados durante el procedimiento quirúrgico.

Por este motivo es por lo que deben difundirse estas guías a todos los niveles y, lo más importante, ponerlas en práctica y continuar con la cultura de seguridad, esperando lograr una atención segura y de calidad para los pacientes. Por último, les invitamos a consultar el documento completo en la página de la Organización Mundial de la Salud.

\section{REFERENCIAS}

1. WHO. Data Global Guidelines for the Prevention of Surgical Site Infection. World Health Organization. ISBN 978924 154988 2016. Disponible en: http://www.who.int/gpsc/ global-guidelines-web.pdf?ua=1

2. Informe Anual 2015 RHOVE. Disponible en: http://www. epidemiologia.salud.gob.mx/dgae/infoepid/inf_rhove. HTML Consultado: 13/nov/2016

3. Andrade ZLE, Sánchez AUC, Martínez RV, Luna TA, Fernández RE. Incidencia de infecciones de sitio quirúrgico en el Hospital Ángeles Mocel durante 2009-2010. Acta Med Grupo Angeles 2013;11(4);167-172.

4. Woelber E, Schrick EJ, Gessner BD, Evans HL. Surgical Infections. 2016;17(5):510-519.

5. Vilar-Compte D, Sandoval S, Gordillo P, De la Rosa M, Sánchez-Mejorada G, Volkow P. Vigilancia de las infecciones de herida quirúrgica. Experiencia de 18 meses en el Instituto Nacional de Cancerología. Salud Pública Mex.1999;41(sup1):44-50.

6. Ángeles-Garay $U$, Velázquez-Chávez $Y$, Molinar-Ramos F, Anaya-Flores VE, Uribe-Márquez SE. Estimación de la estancia adicional en pacientes con infección hospitalaria. Rev Med Inst Mex Seguro Soc. 2009;47(4):387-392.

7. Navarrete-Navarro S, Armehgol-Sánchez G. Costos secundarios por infecciones nosocomiales en dos unidades pediátricas de cuidados intensivos. Salud Pública de México. 1999;4(supl1):51-8.

Hilda Guadalupe Hernández Orozco José Luis Castañeda Narváez Departamento de Infectología/ Comité de Infecciones Asociadas a la Salud Instituto Nacional de Pediatría wuzhi1916@gmail.com

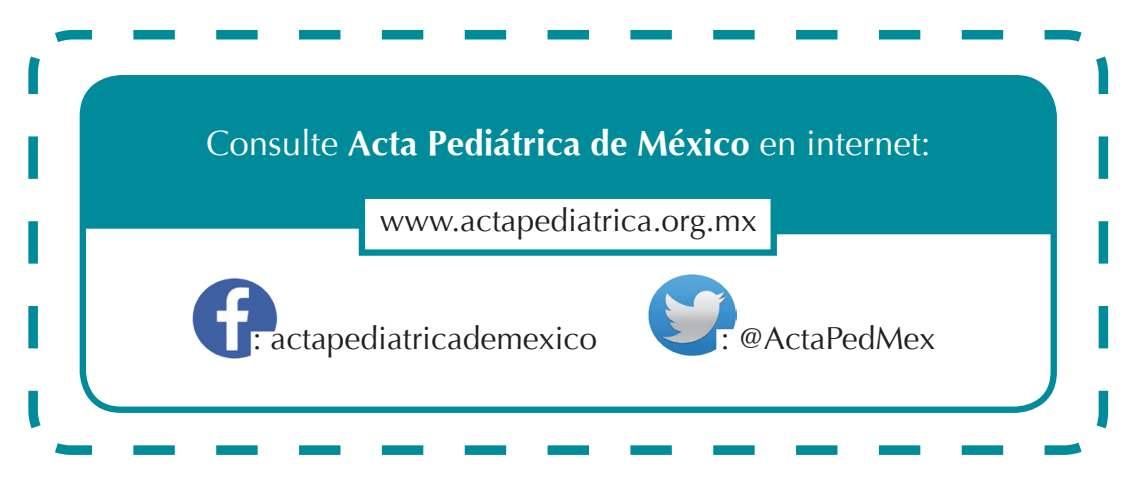

